\begin{tabular}{|lccccc|}
\hline $\begin{array}{l}\text { Social Work/Maatskaplike } \\
\text { http://socialwork.journals.ac.za/pub }\end{array}$ & Werk & $\begin{array}{c}\text { Vol 51 No 3; Issue } \\
\text { doi:http://dx.doi.org/51-3-455 }\end{array}$ & 5 \\
\hline
\end{tabular}

REVIEWING GENDER-BASED VIOLENCE AGAINST WOMEN AND HIVIAIDS AS INTERSECTING ISSUES

Goitseone Leburu, Nomonde Phetlho-Thekisho

Gender-based violence against women continues to be endemic in different forms and in different settings. This form of violence cuts across status, class, religion, race and economic barriers. It occurs at home, in society, in the immediate community, at the work place and in various institutions. This epidemic in most cases also puts women at a greater risk of contracting HIV and Aids. This article reviews gender-based violence and HIV and Aids as intersecting issues. Understanding these phenomena can provide valuable information that could be useful in generating new knowledge within an existing body of knowledge. 


\section{REVIEWING GENDER-BASED VIOLENCE AGAINST WOMEN AND HIV/AIDS AS INTERSECTING ISSUES}

\section{Goitseone Leburu, Nomonde Phetlho-Thekisho}

\section{INTRODUCTION}

This review examines a selected and limited number of topics that are central to genderbased violence (GBV) against women and HIV and AIDS: various forms of violence directed against women; the prevalence of HIV and AIDS among women; the interconnection between GBV and HIV and AIDS; HIV and AIDS risk factors among women; and the Domestic Violence Act (Act 116 of 1998) as a policy that is implemented in South Africa to address GBV. A detailed discussion then follows on the different theoretical frameworks used in this article.

A recent WHO (2013:2) report shows GBV against women to be pervasive globally, and that it is not a small problem that occurs only in some pockets of society, but rather a global public health problem of epidemic proportions requiring urgent action. GBV manifests itself in different forms, some of which are brutal, such as the murder of a targeted woman on account of her sexual orientation, forced pregnancy, honour killings, burning or acid throwing, female genital mutilation, dowry-related violence and rape in armed conflict, trafficking of women for commercial sex work, and sexual harassment and intimidation at work (Morrison, Ellsberg \& Bot, 2004:117). Some GBV cases are subtle and not clearly recognisable. They are not openly acknowledged, as in psychological violence and or abuse. In certain cultural spheres domestic violence is still a private matter hidden from the public gaze and therefore outside the scope of public intervention. In other grossly intolerant situations, same-sex relations are not accepted and therefore "corrective rape" is socially sanctioned and justified (Managa \& Chiroro, 2013:1).

According to Amdie (2005:7), GBV puts women and girls at a great risk of HIV infection and can also make women more vulnerable to HIV through three main mechanisms. First, there is the possibility of direct transmission through coerced sexual acts. Secondly, the trauma associated with violent experiences can impact negatively on later sexual behaviour by increasing the women's HIV risk-taking behaviour. Third, violence or the threat thereof may limit women's ability to adopt safe and protective sexual practices within other on-going relationships and may hinder them from using HIV-related services such as treatment for sexually transmitted infections (STIs), voluntary counselling and testing, and prevention of mother to child transmission services.

\section{VARIOUS FORMS OF VIOLENCE DIRECTED AGAINST WOMEN}

The different forms of GBV are presented below under a number of categories which, though different, are to a large extent intertwined. 


\section{Physical violence}

This is an act that may result in pain, injury, impairment and can even lead to death. Physical violence can take many forms such as beating, shaking, tripping, punching, burning, pulling of hair, slapping, gripping, pushing, pinching, kicking and the use of physical restraints (Seilberger, 2011:694).

Physical violence against women, particularly intimate partner violence (IPV), is a major public health problem and constitutes the highest level violation of women's human rights, based on its visibility and cruelty.

The global prevalence of GBV against women clearly shows this problem has no respect for boundaries, colour and socio-economic status. The figures given by WHO Fact Sheet (2013:1) clearly indicate that about 35\% of women worldwide have experienced either IPV or non-partner sexual violence in their lifetime, with the highest form of violence against women reported in the south-east Asia region (37.7\%), followed by the eastern Mediterranean region (37.0\%); the African region, consistently portrayed as the worst offender, comparatively speaking, surprisingly takes third place at $36.6 \%$.

In South Africa physical violence is the second leading cause of death and an equally leading cause of disability, mostly among women. For instance, the overall death rate from injury among the targeted women as in 2009 was recorded as 157.8 per 100000 population, nearly twice the global average. The rate of intimate femicide in the year 2009 was recorded as six times the global average rate (Seedat, Van Niekerk, Jewkes \& Suffia, 2009:1011-1013). It is challenging to obtain accurate and current statistics, presumably because of the difficult position most abused women find themselves in, resulting in abuse cases going unreported.

This statistical scenario can serve to reflect that dealing with GBV has become second nature for some women in some settings, and in certain situations GBV has been internalised by these very women, with the danger of their socialising their girl children into regarding the violence directed against them as a natural progression of life. A worrying point is that all this violence against women in South Africa takes place in a democratic dispensation in which "women's issues" are placed high on the governments' agenda. The question then is: Where do we go wrong as South Africans?

\section{Sexual violence}

According to Chatora (2013:12), sexual violence constitutes any forced sexual encounter, any attempt to engage in sexual acts forcefully, or even any unwanted sexual comments directed against a person's sexuality, or using coercion of any person regardless of their relationship to the victim. It must be categorically stated that these sexual acts need to be disapproved by the person against whom the acts are directed in order for them to constitute criminal acts.

Millions of women all over the globe, including those in South Africa who are directly exposed to some form of sexual violence, and an even greater number who are forced to live with the fear of its pervasiveness, apparently have made it their "new normal" way of domestic life. A multi-country study conducted by Bywaters, McLeod and Napier 
(2009:110) on domestic violence and women's health in 15 sites and 10 countries found that the proportion of women who had experienced sexual violence by intimate partners in their lifetime ranged from $15 \%$ to $17 \%$, with prevalence for most sites between $29 \%$ and $90 \%$ reported.

South Africa, notoriously known as a violent country, has one of the highest rates of sexual violence against women and children reported in the world. It is rated amongst the leading countries when it comes to violent crimes such as murder and rape against women, in spite of its most progressive Constitution. The violent situation in South Africa approaches endemic proportions. As an illustration of this pervasive form of violence, a study of young women in South Africa (Turmen, 2003:411) found that 30\% of girls said their first intercourse was forced, $71 \%$ had experienced sex against their will, and $11 \%$ had been raped in their lifetime.

Manifestations of the reported sexual assaults are the risk of contracting STIs, including HIV infections, which negatively affect not only the victims physically, socially and psychologically but also significant others (Kalichman \& Simbayi, 2004:68). On this account of the pervasiveness of sexual against women, the South African National Crime Statistics report (2013/14:22) surprisingly showed that sexual assault decreased by $4.9 \%$ (352 cases) during 2013/14 in South Africa. North West recorded the highest decrease with $19.8 \%$ (77 cases), followed by Gauteng with $9.9 \%$ (141 cases) and Eastern Cape with $6.5 \%$ (50 cases).

In real and historic terms, this article contends that the situation outlined above might prove to be more serious if all cases were reported and fairly handled by those in authority, which is rarely the case. Sexual violence does affect women's power and ability to negotiate the conditions of safe sexual intercourse, especially condom use. Sexual violence and rape has possibilities of even turning into a vicious cycle, where a person who has been sexually violated in turn sexually abuses and molests others, especially young helpless girls.

\section{Emotional violence}

Emotional violence, according to Iwaniec (2006:28), in its extreme forms communicates the idea that someone is worthless, flawed, unloved, unwanted and endangered. This form of violence includes spurning, terrorising, isolation, exploitation and denying emotional responsiveness, and entails verbal and non-verbal behaviours of belittling someone, shaming and degrading them, threatening them as well as imposing severe restrictions on them.

This means that emotional violence is not visibly evident on the victims. This inscrutable aspect can also make it difficult for the victim to be believed. Nor can it be used as part of the evidence when reporting the incident to the police (who are mostly not trained in psychotherapy). Perpetrators, as a result, tend to get away with this type of violence. In the worse scenarios it has the possibilities of culminating in mental illhealth, which in South African courts can be a ground for divorce (apparently favouring the perpetrator). 


\section{Economic violence}

Economic violence may take the form of the perpetrator making the victim beg for money or withholding money for basics such as food and sanitary towels (Marsh \& Melville, 2011:349). In other instances this type of violence can also entail forcefully taking and even controlling the money of the victim (the woman) by the perpetrator (the man).

Findings from a study conducted by Development Research in Africa (2011:73) revealed that approximately $48 \%$ of women respondents have been and still are victims of economic abuse. Various indicators were used in the survey to create an understanding of the nature of this abuse. This included having the victims' income spent on the "other woman/women", having their clothes torn off, their belongings sold and their valuable possessions spitefully damaged beyond repair. Other indicators further revealed that $34 \%$ of the perpetrators had exclusive control over household money, $27 \%$ were prevented from knowing about family income/finances, $26 \%$ were prevented from using or accessing family income, with an additional $13 \%$ of the respondents indicating that they were abused and attacked because of household expenditure. This type of violence tends to perpetuate the dependence of the victim on the perpetrator, and entrenching further power over the victim.

From the different types of violence demonstrated above, the question that has been posed and once more reiterated by the researchers of this study is: Why do some women in South Africa continue to stay in such violent relationships? The following serve as possible reasons, as postulated by the WHO (2012:3):

- fear of retaliation;

- lack of alternative means of economic support;

- concern for their children;

- lack of support from family and friends;

- stigma or fear of losing custody of children associated with divorce; and

- hope that the partner will change.

Despite these barriers, many abused women eventually leave their partners, often after multiple attempts and years of violence. By the time that they gather the courage to leave abusive partners, most are infected with the HI virus, and some even end up retaliating by killing their partners. Alternatively, some abused women end up being killed themselves - an eventuality termed femicide.

\section{PREVALENCE OF HIV AND AIDS INFECTION AMONG WOMEN}

UNAIDS Fact Sheet (2014:1) draws a real yet frightening picture, indicating that in 2013 there were some 35 million (33.2 million to 37.2 million) people living with HIV globally. Since the start of the epidemic, around 78 million (71 million to 87 million) have become infected with HIV and 39 million (35 million to 43 million) people have died of AIDS-related illnesses. In 2013 Sub-Saharan Africa recorded 24.7 million (23.5 
million to 26.1 million) people as living with HIV. Women accounted $58 \%$ of the total number of people living with HIV in Sub-Saharan Africa.

The main question posed in this article is: Why this skewed bias in the figures against women? Is it because testing them is part of the medical routine when pregnant? One wonders whether they access and utilise medical facilities in order to check on their HIV status. Or does this indicate the possibilities of being sexually violated and abused, including being raped? The possibilities can also suggest rape within marriages or within an intimate relation. Another indication is that of ill-informed and violent intimate partners refusing to practise safer sex by wearing a condom, resulting in repeated reinfections.

The South African National Antenatal Sentinel HIV \& Syphilis Prevalence Survey (2011:12) points out that the overall HIV prevalence amongst antenatal women in South Africa in 2011 was $29.5 \%$, a decrease of $0.7 \%$ from $30.2 \%$ in 2010 . This decrease is presumably based on a shift in the South African government's position of denial under the Mbeki administration of the causal link between HIV and AIDS, and from claims that anti-retroviral drugs (ARVs) are ineffective and lethally toxic in the face of scientific evidence to the opposite (Mbali, 2004:104). The 2011 HIV prevalence estimate was in line with estimates from 2007-2009. However, the national HIV prevalence estimate amongst the women surveyed has remained stable around $29 \%$ over the past five years (South African National Antenatal Sentinel HIV \& Syphilis Prevalence Survey, 2011:12).

Statistics South Africa (2013:4) takes the HIV prevalence picture even further by providing the HIV prevalence estimates and the total number of people living with HIV from 2002 to 2013 in South Africa. The total number of HIV-positive people in South Africa increased from an estimated 4 million in 2002 to 5.26 million by 2013 . For 2013 an estimated $10 \%$ of the entire population was HIV positive, with approximately $17.4 \%$ of these women being HIV positive as opposed to $15.9 \%$ comprising HIV-positive adults (men and women) within the age range 15-49.

From the figures provided above it is evident that the brunt of the HIV epidemic is borne by women, who are mostly in their reproductive and productive years. The implication of this scenario can also suggest the possibility of high rates of sexual abuse and violence against most South African women, in both intimate and non-intimate relationships manifesting in high rates of HIV and AIDS. The paucity of researched information in this area makes it difficult to provide empirical evidence in this regard.

\section{THE INTERCONNECTION BETWEEN GBV AND HIV/AIDS}

The interconnection between GBV and HIV/AIDS is a complex phenomenon which is not linear but cyclical. This implies that GBV against women does not by itself serve as a causative factor of HIV and AIDS, nor do HIV and AIDS by themselves cause GBV. Ahikire and Mwiine (2012:9) see the cyclic link between HIV and GBV, particularly violence against women, as preconditioning factors of each scourge and as a result of the interplay between them, the scourge becomes self-reinforcing. The WHO (2004:1) 
describes this interconnection as complex and can be understood through the interplay of biological, socio-cultural and economic factors, as further elaborated below.

\section{Biological factors}

Biological factors are about the understanding of a person at intrapersonal or individual level. The point being made here is that much as environmental risk factors of GBV and HIV/AIDS are to be known and highlighted, the starting point ought to be "selfknowledge" of one's biological make-up and functioning as a woman in comparison to men's (bearing in mind that there is no universal "woman").

The biological risk of transmission in a violent sexual encounter can be determined by the type of sexual exposure (for example, whether it is vaginal, anal or oral). HIV transmission risk can equally be higher with the degree of trauma encountered as a result of vaginal lacerations and abrasions which can occur when force is used (WHO Bulletin, 2004:1).

Young women are especially vulnerable to HIV infection through sexual intercourse, because the immature and undeveloped genital tract of girls is more likely to sustain tears during sexual activity, especially with an older and more experienced partner, creating a higher risk of HIV transmission (Turmen, 2003:412). The implications of the higher biological and or physiological susceptibility of women to HIV infection than men point to a need for more gender-specific prevention and intervention mechanisms that are to be tailor-made, over and above generic ones.

\section{Cultural factors}

The Centre for Disease Control and Prevention (2005:1) alludes to the fact that religious beliefs, customs and cultural traditions sometimes place women and young girls directly at risk of HIV and AIDS. For instance, in South Africa the paying of "lobola" (also called "bride price") - a common practice in most South African cultures previously used to serve as modest gifts intended to promote links between families - is now seen and used as an income-generating venture by some families. This is now turning young girls into commodities expected to live up to the customary expectations regarding child rearing and other sexual duties towards their husbands. In such practices young women are often left without a say and cannot negotiate for safer sex.

It is clear from the above discussion there is a need for greater cultural competence in most cultural practices that discriminate against the sexual integrity of women. Adherents of such cultures should be sensitive to women issues, and should equally ensure the dynamic of culture are in line with democratic trends.

\section{Risky partnering with older men}

Whilst age does not to serve as a determining factor in an intimate partner relationship, young women seem more attracted to older men for a variety of reasons, including economic survival. A study by Karim and Karim (2010:318) found that the conditions under which women have sex is mostly determined by their male partner's use of violence and gender-role expectations about love, sex and compliance with the male partner's desires. Because male partners are usually older, the power and maturity 
advantage that they hold creates an environment conducive to sexual coercion. Older partners may also provide financial benefits, thus making the young women's power to negotiate safer sex difficult. Violence in such a space may also be a contributing factor in the spread of the HIV and AIDS epidemic.

In South Africa the findings of the study by Wechsberg, Parry and Jewkes (2010:2) revealed that over the years social norms have favoured age-disparate sex where older men have sexual relations with younger women. Also, in other circles, having sexual relations with a young virgin girl was regarded as safe, even with the possibility of selfcleansing of oneself of the HI virus. As a result many young women were falling prey to such merciless violence and abuse, which led to a spiralling of the prevalence of incest rape and HIV and AIDS among young women.

The fact of the matter is that in reality there can be no policy prescribing who should engage in intimate relations with whom. However, on this score the South African Criminal Law Sexual Offences and Related Matters Amendment Act (Act 32 of 2007) does prohibit adults from engaging in sexual relations with children under the age of 18 years - an offence termed statutory rape. This offence disregards the fact whether the act was in fact consensual, since the child in question is still a minor. What can exacerbate the problem on a practical level, though, can be the non-reporting of such cases.

\section{Violence as a direct result of HIV and AIDS infection}

The findings from Wechsberg et al. (2010:2) in South revealed that gender norms over the years have placed men in control of sexual relations. Such norms have allowed most men overtly and covertly to prescribe and dictate the circumstances and frequency of sex, whether a condom should be used or not, and to an extent culturally condoning marital rape and physical violence against women.

From the above account it can be deduced that the situation in South Africa is unique and complicated in the sense that not only is GBV penetrated by men against women who are not their intimate partners, but that IPV is common including rape with marriage. To further complicate the situation the victims can even be innocent children (girl-children in particular) related to the perpetrators themselves through incest - a deliberate and malicious spread of the HI virus almost within the entire household.

\section{THE DOMESTIC VIOLENCE ACT (ACT 116 OF 1998) AS ONE OF THE POLICIES IMPLEMENTED IN SOUTH AFRICA TO ADDRESS IPV}

Most programmes implemented by women's groups, other pressure groups which are faith-based, including those spearheaded by both men and women, and the government have attempted to address violence against women for many years in South Africa. Many of these programmes are often of a small scale, in most cases not adequately resourced, operating in isolation and on a piecemeal basis, and may not be scaled up easily (WHO, 2004:4). On the other hand, a growing number of HIV and AIDS and reproductive health programmes are also beginning to address violence against women. Many of these interventions, however, have not yet been fully formally evaluated and therefore there is not enough evidence that they work or qualify as part of good practice. 
For the purposes of this article one of the long running policies is examined: the Domestic Violence Act (Act 116 of 1998) and the Domestic Violence Act as amended (Act 55 of 2003). The rationale for choosing this policy is that it has long been implemented and equally been evaluated by different researchers and users hitherto.

The Domestic Violence Act (Act 116 of 1998) was passed after recognising that there is a high incidence of violence in South Africa and that there was some ineffectiveness in services made available to victims of violence in domestic settings. There was also a recognition that most victims of domestic violence are among the most vulnerable members of South African society. The purpose of the Domestic Violence Act (Act 116 of 1998) is to afford victims of domestic violence protection from domestic abuse and violence by ensuring that relevant organs of state give full effect to the provisions of this Act, thereby conveying a message that the state is committed to addressing the problem of domestic violence.

The Domestic Violence Act (Act 116 of 1998) is very explicit about the different types of abuses and violence it responds to. The conditions under which a protection order can be applied for and issued are clearly indicated. The duties of police officers at the scene of a domestic violence incident are well indicated (Domestic Violence Act as amended, Act 55 of 2003:1, 2, 5, 6).

Much as this Act managed to grant a voice and protection to victims of domestic violence, which seemed to be mostly women, weaknesses in implementation are evident. The investigation from the Tshwaranang Legal Advocacy Centre (TLAC) and the Heinrich Böll Foundation (HBF) in Lopes (2013:2) pointed to some challenges experienced regarding its implementation. Some of the discernible gaps were:

- The application form was only available in English, which further complicated the application process for applicants (84\%) who did not speak English as a first language;

- Applying for protection orders was time-consuming. Only $23 \%$ of applicants spent less than an hour in court; the remainder waited between two to six hours, which results in some applicants giving up all hope;

- Applicants were also not always guaranteed to receive support on the same day. This was often dependent on the availability of magistrates;

- Waiting periods between applying for an interim protection order and returning to court for the final protection order hearing varied across the courts - some from as little as two weeks, while at other courts the wait for the final protection order hearing could take up to six weeks;

- For those employed (56\% of the sample), taking time off from work to go to court was challenging and led to financial strains. This was further worsened by delays and the need to return to court multiple times. Time-delays also had significant implications for those who needed protection from abuse; 
- Court clerks did not always fulfil their duties as prescribed by the DVA, including not always providing applicants with sufficient information on what to do or what to expect following the court's granting of the interim protection order; and

- Several complaints were levelled against the police, including delays in attending to call outs, attempts at mediating cases instead of arresting the perpetrator (Lopes, 2013:2).

The results of a hearing on the monitoring of the implementation of the Domestic Violence Act (Act 116 of 1998) by the South African Police Service held by the Portfolio and Select Committees on Women, Children and Persons with Disabilities, on the 28 and 29 October 2009, revealed some of the following as key concerns as well:

Non-compliance - In the case where firearms were involved, these were not always confiscated after being used to threaten victims and the licence of the alleged perpetrator suspended;

Lack of resources - There had, for example, been instances where the police claimed that they had no vehicles available and situations where the areas from which victims called were not in their jurisdiction, particularly in rural areas. As a result, service was not rendered;

Serving of protection orders - It was noted that protection orders often did not serve the purpose they are intended for in that they were not adequately enforced and the victim continued to suffer abuse despite the serving of the protection orders (Matthews, 2012:1).

From these research findings it is evident that most victims of domestic violence/abuse have various problems with the Domestic Violence Act (Act 116 of 1998); these included a language problem in that the Act is written in language which cannot be comprehended by all; long processes followed in applying for protection orders; long waiting periods for protection orders; non-compliance by the police; lack of resources which compromises quality of service; and the lack of enforcement mechanisms for protection orders. From these observations one can conclude that the implementation of the Domestic Violence Act (Act 116 of 1998) is problematic and therefore not fully effective.

\section{THEORETICAL FRAMEWORKS}

\section{Feminist theories}

According to Kirst-Ashman (2007:76), feminism is a philosophy that agitates for equality between men and women, and undermines both the beliefs and actions that differentiate people on the basis of biology and gender. The theory often necessitates providing education and advocacy on behalf of women. It considers the diversity and personal accomplishments of women in relation to their male counterparts. The rationale for the usage of this theory in this article is that a feminist perspective challenges the idea that the potential of both women and men is limited by gender. Rather, the theory proposes that women are not in opposition to men, but that they should be empowered to 
develop their abilities and capabilities in order to achieve optimal wellbeing (Abbott, Wallace \& Tailor, 2005:267).

Yet it must be borne in mind that women do not constitute a homogeneous category, but are different in their individual and collective struggles. There are a variety of feminist theories, but for the purpose of this study liberal, radical and socialist feminism are used to interrogate and understand the situation of women experiencing GBV and HIV/AIDS infection in South Africa.

\section{Liberal feminism}

Liberal feminism is characterised by its focus on equality. It is based on the belief that men and women have the same rational capacities and capabilities. The argument is that men and women should be treated equally, which does not in any way suggest "sameness". If women are provided with the same educational, occupational and political opportunities, the argument goes, they will realise their true potential and no longer be subordinate to men (Abbott et al., 2005:267).

Furthermore, liberal feminism places high premium on rationality, autonomy and choice. Liberal feminists view reason as an important characteristic that is fundamental for moral and political autonomy. Proponents of this theory such as Rwalsian, Baehr and Chamber argue that women's exclusion from the public sphere may inhibit their full capacity to develop and exercise their rationality (McLaren, 2002:5). Therefore, they advocate for full participation and legal equality for women. This theoretical framework also advocates women with men working together within existing legal, political and economic institutions. Ideas such as rights, freedom, justice and equality are seen as objectives to achieve parity for women (McLaren, 2002:5-6).

Liberal feminists believe that men and women are essentially the same species of humanity, though biologically different, because the capacity to reason is the defining characteristic in all human beings. Consequently, liberal feminism argues that relations between the two are not and ought not to be gendered. Therefore, the gender differences in such areas as physical capacities ought not to be seen as important and should not be the basis for determining access to resources and opportunities (Abbott et al., 2005:267).

Payne (2005:253) alludes to an additional factor of liberal feminism in that it also seeks equality between men and women not only in caring responsibilities, but also in workplaces, which until recently had been dominated by men in most countries in the world including in South Africa. The answer is to promote equal opportunities by legislation, and altering the socialisation processes so that children do not grow up accepting their gender inequalities as the norm.

Contextualising this liberal theory within the South Africa situation, it is clear that after the onset of democracy in 1994 South Africa became known internationally for good performance in terms of how gender equality has received prominence. Starting with the country's most progressive Constitution (Act 108 of 1996) and its strong provisions in respect of equality, this to an extent laid the basis for its apparently strong commitment to the discourse of gender equality (RSA MDG, 2013:5). South Africa has also 
introduced a variety of policies and pieces of legislation since 1994 that have directly addressed gender disparities (RSA MDG, 2013:5).

The Organisation for Economic Cooperation and Development (OECD, 2012, as cited in the RSA MDG, 2013:5) states that on paper South Africa has made sterling progress. It is ranked 4th out of 87 countries in the 2012 index and was the top-ranked country in Africa, in terms of its commitment to gender issues (women's issues in particular). As an example, South Africa's success in bringing about gender equality has been most visible in the area of politics, particularly in the national Parliament. In $200943 \%$ of members of parliament in executive positions were women (Gender machinery, 2009:3).

But the question remains: do these impressive numbers of women politicians serve as a genuine measure of commitment to the empowerment of women, or are they merely party political affirmations? The reason for the question is that women's issues seem confined only to the Ministry created for this purpose, which has over the years not been vary stable, and very rarely have issues which include GBV against women and its interconnection with HIV and AIDS been debated rigorously in Parliament from a gender perspective (specifically a women's perspective) by the very women parliamentarians across party political affiliations. Again, have annual commemorations such as the 16 days of activism for no violence against women yielded any positive result in limiting GBV against women?

Even though the government has consistently supported gender equality, efforts to achieve women's equality have yet to make noticeable difference in the lives of ordinary women, particularly rural black women. By implication, policy changes advocating for equality between men and women seem not accompanied by behavioural changes (bearing in mind that behaviour cannot be legislated). For instance, most women still seem to constitute the "reserve army of labour" - where they are the last to be hired and the first to be fired in the South African situation (South African Communist Party Central Committee Report, 2014:1). This situation has possibilities for further entrenching the economic dependence of most women on abusive and violent partners, predisposing them in turn to sexual abuse.

As an illustration, the unemployment rate of women in South Africa remains higher than that of men and the national average. In the first quarter of 2014 the rate of unemployment among women was recorded at $27 \%$, that is $3.3 \%$ points higher than the rate among men and $1.8 \%$ higher than the national rate. Between the fourth quarter of 2013 and first quarter of 2014, the official unemployment rate increased by $1.1 \%$ to $25 \%$. The increase in the official unemployment rate resulted from increases observed in eight provinces, with the largest increases recorded in Northern Cape and Mpumalanga at $4.1 \%$ and $3.2 \%$ respectively. The North-West province unemployment rate among women remained unchanged at $0.4 \%$ points in the first quarter of 2014 , according to the figures provided for 2013 (Statistics South Africa, 2014:xvi). The situation may be different in the non-formal sector which, though highly unregulated, absorbs large numbers of women. 
The conclusion is that equality on paper between men and women should be accompanied by structural changes, and a commitment by all to ensuring the implementation of what is legally constituted on paper.

\section{Radical feminism}

Radical feminism focuses on one aspect of culture namely, patriarchy. Attempts are made to highlight how patriarchy is bred through the socialisation process, which begins in the family, and how patriarchy infiltrates into other sectors of society like religion, education, the economy and politics. The main argument put forth by radical feminism is that patriarchy leads to gender inequality and subordination of women to the extent that females do not have control over their sexuality (Kambarami, 2006:1). Additionally, radical feminists define patriarchy as a social system in which men appropriate all social roles and keep women in subordinate positions. They further state that this social system has managed to survive for so long because its chief psychological weapon is its universality as well as its longevity (Kambarami, 2006:1-2).

Leclerc-Madlala (2000:15) refers to some African cultures which allow the husband to marry as many wives as he wants as an expression of a culture of polygamy, and can even have extra-marital affairs as a bonus. When such a situation obtains, it is the wife who is blamed for failing to satisfy her husband, or for failing to curb his desire. However, should the married woman engage in an extramarital affair, she is labelled as "loose" and this can even be regarded as legitimate grounds for divorce. In addition, married women are expected to be sexually passive and submissive to their husbands, for, after all, men are the initiators of sex and also set the conditions for the sexual encounter. On the same note, women are expected to satisfy the sexual desires of their husbands and partners. As a result, when a husband wants sex, the wife should comply because that is part of the marriage contract. This scenario has seen HIV and AIDS spreading, because most women have become unable to insist on safer sex measures in such situations of infidelity.

Based on the above accounts of how patriarchy is sustained and entrenched, the suggestion would be making "the private" sphere of the home "public" and therefore open to scrutiny and intervention. At the same time, there is a need, especially in the $21^{\text {st }}$ century, to move away from traditional gender roles that are prescriptive and define women solely in reproductive terms. Emphasis needs to be placed on strategic gender roles that consider people's differences, including recognition of the productive capacities in women as well.

\section{Marxist feminism}

Socialist feminists argue that in capitalist systems material and economic factors underlie women's subservience to men, because patriarchy has its roots in private property. Capitalism intensifies patriarchy by concentrating wealth and power in the hands of small number of men as wage earners as well as possessors and inheritors of property. Secondly, for a capitalist economy to succeed, it must define women as consumers, persuading them that their needs will be met through their increasing consumption of goods. Capitalism relies on women to offer labour for free in homes by 
caring and cleaning. Socialist feminists have called for a restructuring of family, the end of slavery and the introduction of collective means for carrying out child-rearing, caring and household maintenance at a cost (Giddens, 2006:470).

Social feminists view the sexual and gender division of labour as helping to create and maintain gender differences and gender discrimination. The sexual division of labour takes places within the home and in the public sphere. In the domestic sphere the sexual division of labour includes reproductive work such as bearing and rearing children as well as other household tasks such as shopping, cooking and cleaning. In the public sphere the sexual division of labour includes divisions along traditional gender lines such as more men in manual jobs that require heavy lifting and more women in the service sector and secretarial office work. The sexual division of labour perpetuates and reinforces the gender differences which are evident in multiple social relations (heterosexual marriage, traditional family arrangements including women as primary caretakers of children, women's economic dependence on men and the state). Thus Marxist feminists call for a change in the sexual division of labour and the social relations supported by such a division (McLaren, 2002:11).

South Africa has made progress in terms of women's empowerment and the reduction of discrimination towards women in the workplace; yet this has only been the beginning of a longer journey, particularly with regards to the progress that has still to be made in the private sector. In 2009, for instance, the representation of women at senior levels of the public service increased to an average of $36.1 \%$, and women made up $26 \%$ of the higher courts and 40\% of the lower courts (International Women's Forum, 2011:22).

Accordingly to Segooa in Agenda (2012:96-97), the findings of the Equity Commission's (EEC) 10th annual report of 2010 - including those of the Commission on Gender Equality's (CGE) 2008 report on gender equality in the private sector in South Africa - revealed that the private sector is performing dismally in terms of gender transformation in the workplace. The EEC's Report revealed that women were predominately represented in administrative as opposed to policy-making and senior managerial functions, with black women comprising a mere $6 \%$ of those recruited, and $2 \%$ of those promoted to top management positions. Only about $5 \%$ then benefitted from skills development programmes.

A central question for the writers of this article is whether the women in positions of power, who have thereby been affirmed, have become truly empowered or serve only as tokens of affirmative action. In most cases systems and structures of discrimination seem to remain intact, or are merely reformed with women added on to give the company a façade of democratic equity. On this score, according to Slater (2014:339), the beneficiaries of affirmative action have been the better educated and skilled among the designated groups, while marginalised and vulnerable groups (presumably black rural women) have benefitted less from affirmative action.

\section{Ecological practice perspective}

The ecological practice perspective is used to understand the coping patterns of people and their environment so that a better match can be attained between a person's needs 
and the characteristics of his or her environment. This perspective gives attention to both internal and external factors of the person's physical and social environment. It does not view people as passive reactors to their environments, but rather as being involved in dynamic and reciprocal interactions with them (Zastrow, 2009:49). This perspective is used to understand the interdependence and interrelationship between women and their environment.

Payne (2005:150) further explains that the ecological perspective focuses on the interrelational transactions between systems and stresses that all existing elements within an ecosystem play an equal role in maintaining balance of the whole. The ecological approach can be best understood as looking at persons, families, cultures, communities and policies to identify strengths and weaknesses in the transactional processes between these and their environment, and intervene where necessary: they are "people in an environment". The relationship between them and their environment is reciprocal: each influences the other over time.

A focus on the person-in-environment assists people to address problems, needs and aspirations that are associated with obstacles that impede successful accomplishment of transitional and environmental tasks. People generally experience problems when there is a poor fit between needs and wants and the resources available in their environments (Compton, Galaway \& Cournoyer, 2005:7).

There are various environments (factors) within which people can be understood. For the purpose of this study the different environments within which women can be understood are examined in the terms provided by Swanepoel and De Beer (2006:11-13), including the viewpoints of Chirimuuta (2006:71):

- The psychological environment: This consists of the attitude people display towards life around them. Most women in South Africa experience life in their own different ways, which in turn makes them unique and different from each other. Thus one cannot refer to their universal problems. Different dynamics of their GBV and HIV/AIDS issues are to be highlighted;

- The social environment: This consists of institutions such as the primary institution of the family and the secondary institutions such as the school and church, clubs and interest groups that have a bearing on people's lives. For example, some institutions like cultural clubs in some communities emphasise the subservience of women. Women are taught to be humble and submissive to their husbands. This can also be seen in children, where boys tend to grow up believing that they possess more power and control over girls - a form of gender division of resources and opportunities;

- The political environment: This entails different power structures, either traditional, coercive or democratic. Political systems and parties, policies, legislative and state institutions are also examples of the political environment. These types of environments are about gaining access to resources in order to satisfy needs;

- The cultural environment: The cultural environment consists of the values and mores of a society. These values and mores are often spoken of as constituents of the 
traditions of a people. Culture creates and contains taboos and provides a framework according to which people act and react to daily life;

- The economic environment: This refers to the rate of employment, presence and activity of commerce and industry, and the presence and scope of informal economic activities. The society is also economically layered so that very poor, poor people and those who are better off are found in distinct groups (Chirimuuta, 2006:71; Swanepoel \& De Beer, 2006:11-13).

\section{The risk factors associated with GBV against women}

In an attempt to understand the risk factors associated with GBV against women, Ellsberg and Heise (2005:2) suggests that there may not be one single factor, but rather a whole range of variables which can increase or reduce a woman's risk for experiencing GBV. It must be recognised that risk factors are not causes, but they are complex and occur at four different levels that are embedded in concentric circles (see Figure 1).

\section{FIGURE 1}

\section{THE ECOLOGICAL PRACTICE PERSPECTIVE}

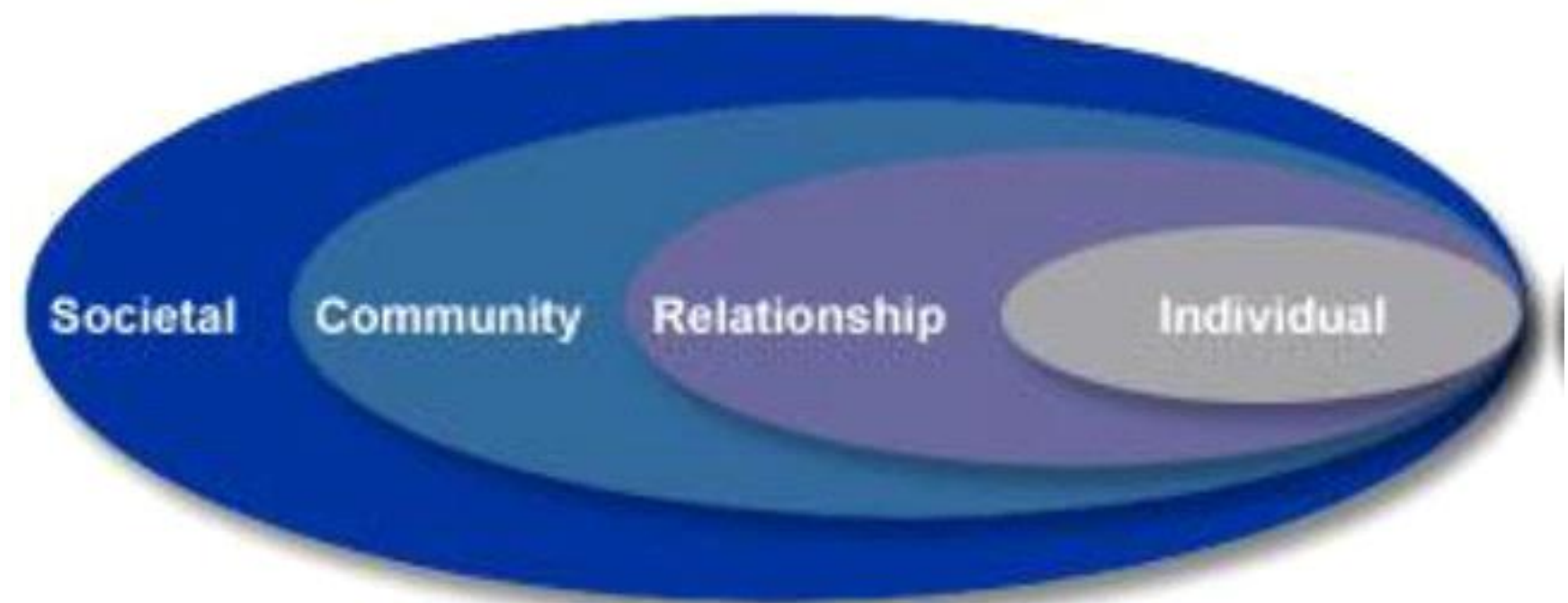

Source: WHO - World Report on Violence and Health, 2002

\section{Individual level}

The first level identifies biological and personal history factors that increase the likelihood of becoming a victim or perpetrator of GBV. Some of these factors are age, education, income, alcohol abuse, or history of abuse (WHO, 2002:15). As an illustration, alcohol abuse is an epidemic in South Africa. The reason for looking into alcohol abuse and GBV in this study is based on the fact that the euphoria from consuming the alcohol is blamed and would in most cases serve as circumstantial evidence, over and above the perpetrators taking responsibility. The use of alcohol in South Africa is among the highest in Africa, with a total adult per capita alcohol consumption of 9.5 litres of alcohol per year. Furthermore, alcohol is seen as a critical driver of violence and the second highest contributor to the burden of disease after HIV/AIDS (Peltzer \& Pengpid, 2013:14). 
The problem of alcohol abuse by men and the aggravated incidence of GBV against women is a global problem. A cross-sectional survey conducted in Nigeria found that a history of alcohol consumption by male partners was significantly associated with reports of physical violence against their intimate female partners (Balogun, Owoaje \& Fawole, 2012:6). One American study used the "Sexual Expressions Survey" tool as a questionnaire to ask participants to describe events that constitute various types of sexual assault against women. The findings indicated that the alcohol consumption of the male perpetrators was linearly related to their aggressiveness against women (Smyth, 2013:261).

In a survey among men in South Africa, Peltzer and Pengpid (2013:14) found that perpetration of violence against women was correlated with a greater likelihood of problematic drug and alcohol abuse by the male perpetrator. The study further argued that alcohol increases sexual aggression as much as it increases the desire to commit violent sexual acts, and some men purposely drink as an excuse to engage in nonconsensual behaviours.

\section{Relationship level}

The second level includes factors that increase the risk of GBV against women because of relationships with peers, intimate partners and family members. A person's closest social circle - peers, partners and family members - can influence their behaviour and contributes to their violent behaviour. Learning about violence within a family constitutes a form of orientation and internalising nascent violent dispositions from the relational aspect.

As found in a study conducted in South Africa by Khumalo, Msimanga and Bollach (2013:9), GBV has a significant effect on children, whether those children are also direct victims of abuse or witnesses to the violence itself. The researchers found that witnessing family violence in childhood is highly associated with a greater likelihood that the children become either perpetrators or victims of violence later on in their lives. With a grown-up woman who experiences GBV, studying her life history often points to a history of violence against her in her family of orientation. The study further found that with most men, their history of violence started in childhood when they witnessed violence between parents. McDonald, Jourilies, Jart and Minze (2008:95) equally showed that children in families characterised by men's severe violence are more likely to externalise and internalise violence problems than children in families with no violence.

\section{Community level}

The third level explores the settings, such as schools, workplaces and neighbourhoods, in which social relationships occur and seeks to identify the characteristics of these settings that are associated with becoming victims or perpetrators of GBV. Unemployment is a factor experienced in most settings.

The frustrations of unemployment and irregular employment have been linked to violence in general in South Africa. A case in point is the notorious and brutal 
xenophobic attacks on foreign nationals in 2008, which have been blamed on the high rate of unemployment in South Africa; such attacks have become a regular phenomenon in recent years (Neocosmos, 2010:9). Also the high levels of violence in South Africa could be attributed to the violent legacy of apartheid, which have left the high rates of unemployment involving gross economic and political inequality. Despite its impressive Constitution, South Africa still has highest levels of inequalities between affluence and poverty existing side by side. There are between $45 \%$ and $55 \%$ of the population that are categorised as poor and between $20 \%$ and $25 \%$ living in extreme poverty as a consequence of the high rates of unemployment in the country (Mcube \& Harber, 2013:3).

This interpretation is supported by a longitudinal study conducted on risk and protective factors in intimate partner violence in Bangalore in the south of India (Krishnan, Rocca, Hubbard, Subbiah, Edmeades \& Padian, 2010:139-140). The study population was characterised by high levels of unemployment. Over two thirds of women who had ever experienced domestic violence reported that their husbands had difficulty finding or keeping a job.

The implication is that with most men unemployed, and therefore unable to support their families financially, GBV against their women partners is used to exert their apparently lost authority.

\section{Societal level}

The fourth level views broad societal aspects that help create a climate in which GBV is promoted. These aspects can include the health, economic, educational and social policies and factors that help to maintain economic or social inequalities within a society.

Research conducted by Dunklea, Jewkes, Brown, Grayd, McIntyre and Harlow (2004:1590) on transactional sex among women in Soweto, South Africa, found that $21 \%$ of women attending antenatal clinics reported having engaged in sexual relations for material gain with a man other than their intimate partners. The report further indicated that the women who reported such transactional sex had a $100 \%$ chance of testing HIV positive at the time of the interview. Transactional sex was also more likely to be indulged in by women who also reported having experienced violence by intimate male partners. In other words, poverty acts as a preconditioning factor for violence against women in instances where women compromise their actions and behaviour for material gain and survival.

It can be concluded from the discussion on the ecological practice perspective that a holistic view of the position of women is possible through understanding them in relation to their reciprocal and adaptive transactions with their environment.

\section{CONCLUSION}

A review from various sources was conducted to understand the background of GBV and HIV and AIDS globally and in South Africa, and to gain an understanding of women's status in relation to men and the factors that contribute to the phenomenon of 
GBV and HIV and AIDS. The results of the review reveal that the escalating rate of GBV and HIV impacts negatively on the total wellbeing of women specifically and the quality of human life in the communities generally. Various theoretical frameworks were analysed to gain a deeper understanding of what lies behind GBV against women. A feminist theoretical framework explained women's status in relation to men and provided ways to redress existing inequalities between men and women. The ecological perspective enabled an analysis of the various human ecosystem levels within which women's condition can be understood holistically with respect to the GBV directed against them.

\section{REFERENCES}

ABBOTT, P., WALlACE, C. \& TYLER, M. 2005. An introduction to Sociology: feminist perspectives. Canada: Routledge Publishers.

AGENDA. 2012. Empowering women for gender equity: weaknesses in South Africa's progress with women's equality and the Millennium Development Goals. [Online] Available: http://dx.doiorg/10.1080/10130950.2012.674260 [Accessed: 02/07/2012].

AHIKIRE, J. \& MWIINE, A.A. 2012. Addressing the links between gender-based violence and HIV in the Great Lakes region. Country Report Uganda. Kampala, United Nations Educational, Scientific and Cultural Organization: Unpublished.

AMDIE, G. 2005. Gender based violence \& the risk of HIV infection among women attending voluntary counselling and testing services in Addis Ababa. Ethiopia: Addis Ababa University. (MA Thesis)

BALOGUN, M.O., OWOAJE, E.T. \& FAWOLE, O.I. 2012. Intimate partner violence in Southwestern Nigeria: are there rural-urban differences? Women Health, 52(7):627645.

BYWATERS, P., McLEOD, E. \& NAIPER, L. 2009. Social work and global health inequities: practice and policy developments. Bristol: Policy Press.

CHATORA, B.E. 2013. The role of gender-based violence in HIV transmission among women in Lusaka Zambia. Western Cape: Stellenbosch University Publishers.

CENTRE FOR DISEASE CONTROL AND PREVENTION. 2005. National vital statistic report. Department of Health and Human Sciences: Unpublished.

CHIRIMUUTA, C. 2006. Gender and the Zimbabwe Education Policy: empowerment of perpetuation of gender imbalances. Unpublished.

COMPTON, B.R., GALAWAY, B. \& COURNOYER, B. 2005. Social work processes. Belmont: Brokes/Coles Publishers.

DEVELOPMENT RESEARCH IN AFRICA. 2011. Economy \& violence. UNCTAD: United Nations Publications. 
DUNKLEA, K.L., JEWKES, R.K., BROWN, H.C., GRAYD, G.E., McINTYRE, J.A. \& HARLOWA, S.D. 2004. Transactional sex among women in Soweto, South Africa: prevalence, risk factors and association with HIV infection. Social Science \& Medicine (59):1581-1592.

ELLSBERG, M. \& HEISE, L. 2005. Researching violence against women: a practical guide for researchers and activists. Washington DC: World Health Organization.

GIDDENS, A. 2006. Sociology. Cambridge: British library Publishers.

INTERNATIONAL WOMEN'S FORUM. 2011. The status of women in South Africa: a preliminary report incorporating the findings of consultative roundtable discussions on Women Empowerment in South Africa. Project Report prepared by Frontier Advisory - International Women's Forum (IWF) South Africa. Unpublished.

IWANIEC, D. 2006. Child \& family social work: risk and resilience in cases of emotional abuse. Child and Family Social Work, 11(1):72-82.

KALICHMAN, S.C. \& SIMBAYI, L.C. 2004. Sexual history and risks for sexually transmitted infections among women in an African township in Cape Town, South Africa. AIDS CARE, 16(6):681-689.

KAMBARAMI, M. 2006. Femininity, sexuality and culture: patriarchy and female subordination in Zimbabwe. Alice: University of Fort Hare. (MA Thesis)

KARIM, Q.A. \& KARIM, S.S.A. 2010. HIV and AIDS in South Africa. Cape Town: Cambridge University Publishers.

KHUMALO, B., MSIMANGA, S. \& BOLLACH, K. 2013. Too costly to ignore the economic impact of gender-based violence. Unpublished.

KIRST-ASHMAN, K.K. 2007. Understanding generalist practice. Belmont: Thomson Brooks/Cole Publishers.

KRISHNAN, S., ROCCA, C.H., HUBBARD, A.E., SUBBIAH, K., EDMEADES, J. \& PADIAN, N.S. 2010. Do changes in spousal employment status lead to domestic violence? Insights from a prospective study in Bangalore. India. Social Science \& Medicine, 70(1):136-143.

LECLERC-MADLALA, S. 2000. Silence, AIDS and sexual culture in Africa. Aids Bulletin, 9(3):27-30.

LOPES, C. 2013. Criminal justice responses: assessing the implementation of the DVA in Gauteng HBS/TLAC Launch of Shadow Report. Johannesburg: Unpublished.

MANAGA, A. \& CHIRORO, B. 2013. The scourge of gender-based violence in South Africa: Nordic Africa Institute Presentation paper. Unpublished.

MARSH, I. \& MELVILLE, G. 2011. Moral panics \& the British Media: a look at some contemporary folk devils. Liverpool: University of Liverpool Publishers. 
MATTHEWS, T. 2012. Reviewing domestic violence and the South African Police Services. Unpublished.

MBALI, M. 2004. Aids discourse and the South African State: Government denialism and post-apartheid AIDS policy making in transformation. South Africa. Unpublished.

McDONALD, R., JOURILIES, E.N., JART, C.D. \& MINZE, L.C. 2008. Children's adjustment in families characterised by men's violence towards women: does family violence matter. Dallas: Southern University Publishers.

MCUBE, V. \& HARBER, C. 2013. Dynamics of violence in South African Schools. Pretoria: University of South Africa Publishers.

McLAREN, M. 2002. Feminism, Foucault \& embodied subjectivity. Albany, NY: SUNY Publishers.

MORRISON, A., ELLSBERG, M. \& BOTT, S. 2004. Addressing gender-based violence in Latin America \& Caribbean Region: critical review of interventions. World Bank Policy Research Working Paper 3438. Unpublished.

NEOCOSMOS, M. 2010. From "foreign natives" to "native foreigners": explaining xenophobia in post-apartheid South Africa. Dakar: CODESRIA.

PAYNE, M. 2005. Modern social work theory. New York: Palgrave Macmillan Publishers.

PELTZER, K. \& PENGPID, S. 2013. The severity of violence against women by intimate partners and associations with perpetrator alcohol and drug. African Safety Promotion Journal, 11(1):1-24.

RSA MDG (Republic of South Africa Millennium Development Goals Report). 2013. The South Africa I know, the South Africa I understand. Pretoria: Statistics South Africa Publishers.

SEEDAT, M., VAN NIEKERK, A., JEWKES, R., SUFFIA, S. \& RATELE, K. 2009. Violence and injuries in South Africa: prioritising an agenda for prevention. Lancet, 37(4):1011-1022.

SEILBERGER, C.D. 2011. Encyclopaedia of Applied Psychology. Oxford: Elsevier Academic Publishers.

SLATER, J. 2014. The ethical demise of the political policy of affirmative action as a motive for enhancing women and education in South Africa: a double setback of a reverse strategy. Studia Historiae Ecclesiasticae, 40 (Supplement):239-348.

SMYTH, M. 2013. Ecological community, the sense of the world and senseless extension. Chicago: University of Chicago Publishers.

SOUTH AFRICA. 1996. Constitution of the Republic of South Africa. Act 108 of 1996. Government Gazette. Cape Town: Government Printer. 
SOUTH AFRICA. 2007. Criminal Law (Sexual Offences and Related Offences and Related Matters) Amendment. Act 32 of 2007. Government Gazette. Cape Town: Government Printer.

SOUTH AFRICA. 1998. Domestic Violence Act 116 of 1998. Government Gazette. Cape Town: Government Printer.

SOUTH AFRICA. 2003. Domestic Violence Act as amended Act 55 of 2003. Government Gazette. Cape Town: Government Printer.

SOUTH AFRICAN COMMUNIST PARTY CENTRAL COMMITTEE REPORT. 2014. Going to the root of the problem - SACP. [Online] Available: http://www. politicsweb.co.za/documents/going-to-the-root-of-the-problem-sacp.

[Accessed: 22/06/2015].

SOUTH AFRICAN NATIONAL ANTENATAL SENTINEL HIV \& SYPHILIS PREVALENCE SURVEY. 2011. Pretoria: Department of Health.

SOUTH AFRICAN NATIONAL CRIME STATISTICS REPORT. 2013/14. Pretoria: South African Police Service.

STATISTICS SOUTH AFRICA. 2013. Mid-year population estimates. Pretoria: Statistics South Africa.

STATISTICS SOUTH AFRICA. 2014. Quarterly Labour Force Survey. Pretoria: Statistics South Africa.

SWANEPOEL, H. \& DE BEER, F. 2006. Community Development: breaking the cycle of poverty. Durban: International Publishing (Southern Africa).

TURMEN, T. 2003. Gender and HIV and AIDS: International Federation of Gynaecology and Obstetrics. Switzerland: Elsevier Science Ireland Publishers.

UNAIDS fact Sheet. 2014. Global Statistics. [Online] Available: www.unaids.org/en/ resources/presscentre/factsheets. [Accessed: 10/03/2015].

WECHSBERG, W.M., PARRY, C. \& JEWKES, R.K. 2010. Drugs, sex, and genderbased violence: the intersection of the HIV/AIDS Epidemic with vulnerable women. RTT Press Public 1005. Research Triangle Park NC RTT Press. doi. 10 3768/rtipress 2010 PB 00011005.

WHO BULLETIN. 2004. Violence against women. Geneva: World Health Organization Publishers.

WHO. 2002. World Report on Violence and Health. Geneva: World Health Organization Publishers.

WHO. 2004. Violence against Women and HIV/AIDS: critical intersections of intimate partner violence and HIV/AIDS. Geneva: World Health Organisation Publishers. 
WHO. 2012. Putting women first: ethical and safety recommendations for research on domestic violence against women. Department of Gender and Women's Health Family and Community Health. Geneva: World Health Organization Publishers.

WHO. 2013. Global and regional estimates of violence of violence against women: prevalence and health effects of intimate partner violence and non-partner sexual violence. Geneva: World Health Organization.

WHO FACT SHEET. 2013. Intimate partner and sexual violence against women. Geneva: World Health Organization.

ZASTROW, C. 2009. Introduction to social work and social welfare: empowering people. Belmont: Brooks/Coles Publishers.

Ms Goitseone Leburu, Social Worker, Ditsobotla Service Point, Department of Social Development; Dr Nomonde Phetlho-Thekisho, North-West University, Mafikeng Campus, South Africa. 